\title{
In Vivo Assessment and Dosimetry of 2 Novel PDE10A PET Radiotracers in Humans: ${ }^{18}$ F-MNI-659 and ${ }^{18}$ F-MNI-654
}

\author{
Olivier Barret ${ }^{1}$, David Thomae ${ }^{1}$, Adriana Tavares ${ }^{1}$, David Alagille ${ }^{1}$, Caroline Papin ${ }^{1}$, Rikki Waterhouse ${ }^{2}$, \\ Timothy McCarthy ${ }^{2}$, Danna Jennings ${ }^{1}$, Ken Marek ${ }^{1}$, David Russell ${ }^{1}$, John Seibyl ${ }^{1}$, and Gilles Tamagnan ${ }^{1}$ \\ ${ }^{I}$ Molecular NeuroImaging, LLC, New Haven, Connecticut; and ${ }^{2}$ Pfizer Global R\&D, Groton, Connecticut
}

Phosphodiesterase (PDE) 10A is an enzyme involved in the regulation of cyclic adenosine monophosphate and cyclic guanosine monophosphate and is highly expressed in medium-sized spiny neurons of the striatum, making it an attractive target for novel therapies for a variety of neurologic and psychiatric disorders that involve striatal function. Potential ligands for PET imaging of PDE10A have been reported. Here, we report the first-in-human characterization of 2 new PDE10A radioligands, 2-(2-(3-(1-(2-fluoroethyl)-1H-indazol-6-yl)-7-methyl-4-oxo3,4-dihydroquinazolin-2-yl)ethyl)-4-isopropoxyisoindoline-1,3-dione $\left({ }^{18} \mathrm{~F}-\mathrm{MNI}-654\right)$ and 2-(2-(3-(4-(2-fluoroethoxy)phenyl)-7-methyl-4-oxo3,4-dihydroquinazolin-2-yl)ethyl)-4-isopropoxyisoindoline-1,3-dione $\left({ }^{18} \mathrm{~F}-\mathrm{MNI}-659\right)$, with the goal of selecting the best one for use in future studies interrogating pathophysiologic changes in neuropsychiatric disorders and aiding pharmaceutical development targeting PDE10A. Methods: Eleven healthy volunteers participated in this study $\left({ }^{18} \mathrm{~F}-\mathrm{MNI}-\right.$ 654 test-retest, 2 men; ${ }^{18} \mathrm{~F}-\mathrm{MNI}-659$ test-retest, 4 men and 1 woman; ${ }^{18} \mathrm{~F}-\mathrm{MNI}-659$ dosimetry, 2 men and 2 women). Brain PET images were acquired over $5.5 \mathrm{~h}$ for ${ }^{18} \mathrm{~F}-\mathrm{MNI}-654$ and over $3.5 \mathrm{~h}$ for ${ }^{18} \mathrm{~F}-\mathrm{MNI}-659$, and pharmacokinetic modeling with plasma- and reference-region (cerebellar cortex)-based methods was performed. Whole-body PET images were acquired over $6 \mathrm{~h}$ for ${ }^{18} \mathrm{~F}-\mathrm{MNI}-659$ and radiation dosimetry estimated with OLINDA. Results: Both radiotracers were similarly metabolized, with about $20 \%$ of intact parent remaining at 120 min after injection. PET time-activity data demonstrated that ${ }^{18} \mathrm{~F}-\mathrm{MNI}-654$ kinetics were much slower than ${ }^{18} \mathrm{~F}-\mathrm{MNI}-659$ kinetics. For ${ }^{18} \mathrm{~F}-\mathrm{MNI}-659$, there was good agreement between the Logan and simplified reference tissue models for nondisplaceable binding potential $\left(\mathrm{BP}_{\mathrm{ND}}\right)$, supporting noninvasive quantification, with test-retest variability less than $10 \%$ and intraclass correlation greater than 0.9 . The ${ }^{18} \mathrm{~F}-\mathrm{MNI}-659$ effective dose was estimated at $0.024 \mathrm{mSv} / \mathrm{MBq}$. Conclusion: PET imaging in the human brain with 2 novel PDE10A ${ }^{18} \mathrm{~F}$ tracers is being reported. Noninvasive quantification of ${ }^{18} \mathrm{~F}-\mathrm{MNI}-659$ with the simplified reference tissue model using the cerebellum as a reference is possible. In addition, ${ }^{18} \mathrm{~F}-\mathrm{MNI}-659$ kinetics are fast enough for a good estimate of $\mathrm{BP}_{\mathrm{ND}}$ with $90 \mathrm{~min}$ of data, with values around 3.0 in the basal ganglia. Finally, ${ }^{18} \mathrm{~F}-\mathrm{MNI}-659$ dosimetry is favorable and consistent with values reported for other PET radiotracers currently used in humans.

Key Words: PDE10A; PET imaging; kinetic modeling; test-retest; dosimetry

J Nucl Med 2014; 55:1297-1304

DOI: 10.2967/jnumed.113.122895

\footnotetext{
Received Mar. 17, 2014; revision accepted Mar. 27, 2014.

For correspondence or reprints contact: Olivier Barret, Molecular Neurolmaging (MNI), LLC, 60 Temple St., Ste. 8B, New Haven, CT 06510. E-mail: obarret@mnimaging.com

Published online Jun. 2, 2014.

COPYRIGHT (c) 2014 by the Society of Nuclear Medicine and Molecular Imaging, Inc.
}

C yclic nucleotides are major regulatory molecules of both short-term and long-term function in every known neuronal population. The modulation of cyclic nucleotides, especially cAMP (cyclic adenosine monophosphate), is a major target of many pharmaceutical agents for a large number of diverse brain disorders. Specificity has usually been achieved by modulating specific G-protein-coupled receptors that in turn regulate adenyl cyclase. Phosphodiesterases (PDEs), grouped into 11 families (PDE1-PDE11), act by catalyzing the breakdown of cAMP or cGMP (cyclic guanosine monophosphate) and allow additional opportunities to target specific neuron types, brain regions, disease states, or cyclase pathways that are not regulated by G-protein-coupled receptors (1-4).

PDE10A, highly expressed in the brain and strongly enriched in medium spiny neurons of the striatum, particularly in primates $(5,6)$, catalyzes breakdown of both cAMP and cGMP (7) and is the major source of cAMP breakdown in the striatum among PDEs (8). PDE10A is therefore an attractive target for novel therapies for a variety of neurologic and psychiatric disorders that involve striatal function (9), including Parkinson disease (10), Huntington disease $(11,12)$, schizophrenia $(13,14)$, memory disorders $(15)$, depression, and addiction (16). Animal models of Huntington disease have shown that PDE10A expression is an extremely sensitive marker of striatal neuron loss $(12,17)$, and Parkinson disease models have been used to demonstrate possible roles of PDE10A in both the early motor symptoms and the late complications of Parkinson disease due to prominent PDE10A-dependent dysregulation of corticostriatal signaling $(10,18)$. Developing imaging agents to accurately and sensitively interrogate PDE10A in vivo would greatly help in understanding changes in PDE10A in human brain disorders and speed the development of potential therapeutics targeting this enzyme.

Potential ligands for PET imaging of PDE10A have been reported (19-24). Papaverine, a widely used inhibitor of PDE10A activity, lacked suitable imaging characteristics when ${ }^{11} \mathrm{C}$-labeled (22). ${ }^{11} \mathrm{C}-\mathrm{MP}-10$, another PDE10A inhibitor, was found to have good imaging qualities $(19,24)$ despite a radiolabeled metabolite capable of penetrating the blood-brain barrier (24). ${ }^{18} \mathrm{~F}-J N J 41510417$ was demonstrated to have good pharmacologic and anatomic specificity in rodent PET studies (23) but had a radiometabolite entering the brain. More recently, human studies with ${ }^{18} \mathrm{~F}-J N J 42259152$ were reported $(20,25)$.

Previously, we reported on the evaluation in nonhuman primates of the 2 novel PDE10A radiotracers 2-(2-(3-(1-(2-fluoroethyl)-1Hindazol-6-yl)-7-methyl-4-oxo-3,4-dihydroquinazolin-2-yl)ethyl)4-isopropoxyisoindoline-1,3-dione ( $\left.{ }^{18} \mathrm{~F}-\mathrm{MNI}-654\right)$ and 2-(2-(3-(4(2-fluoroethoxy)phenyl)-7-methyl-4-oxo-3,4-dihydroquinazolin-2-yl) ethyl)-4-isopropoxyisoindoline-1,3-dione ( $\left.{ }^{18} \mathrm{~F}-\mathrm{MNI}-659\right)$ and their PDE10A selectivity against MP-10 (26). Here, we report about 


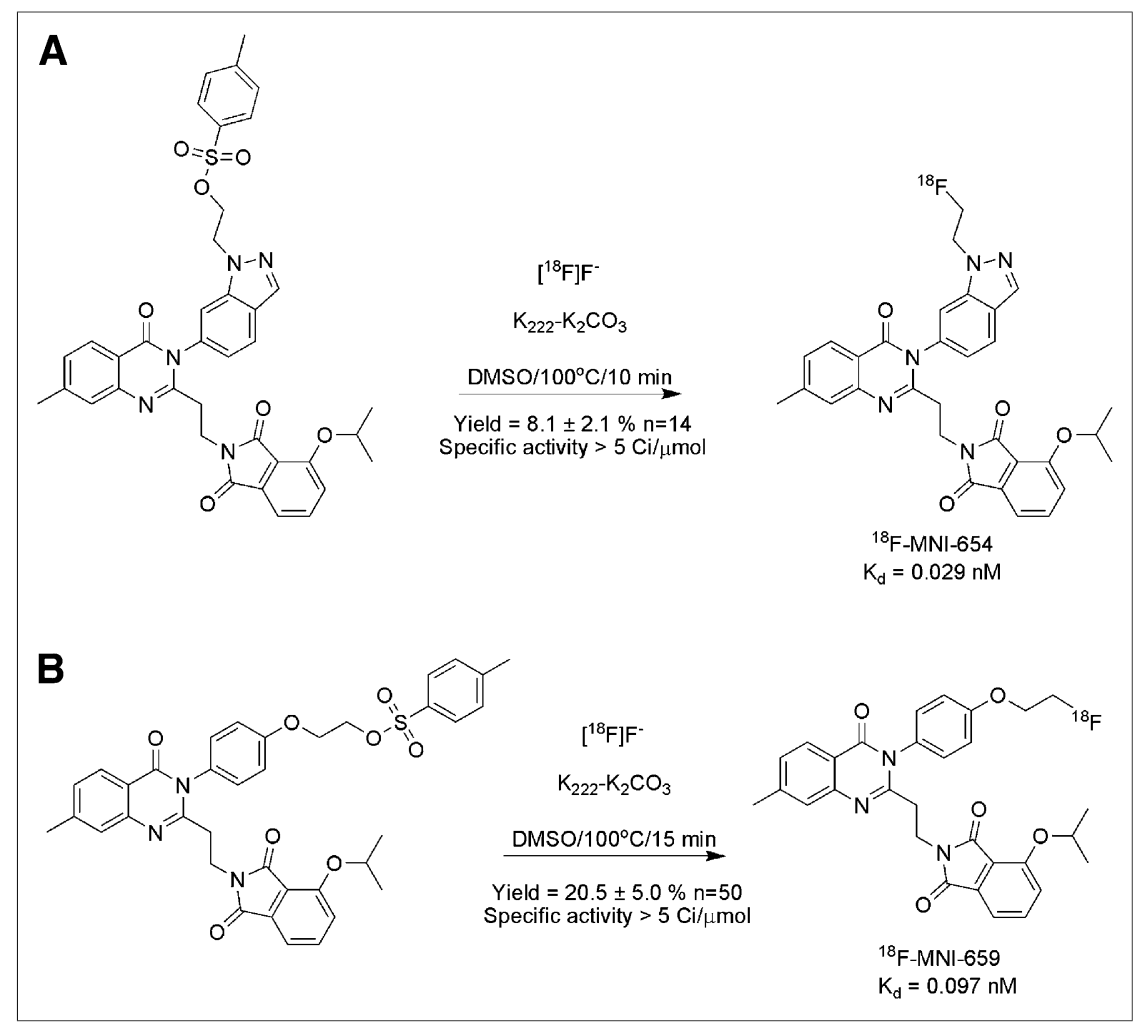

FIGURE 1. Radiosynthesis of ${ }^{18} \mathrm{~F}-\mathrm{MNI}-654$ (A) and ${ }^{18} \mathrm{~F}-\mathrm{MNI}-659$ (B) from their tosylate precursors. Specific activity $=185 \mathrm{GBq} / \mu \mathrm{mol}(5 \mathrm{Ci} / \mu \mathrm{mol})$. $\mathrm{DMSO}=$ dimethyl sulfoxide.
PDE10A extract were diluted in $30 \mathrm{~mL}$ of assay buffer $(50 \mathrm{mM}$ Tris- $\mathrm{HCl}, \mathrm{pH} 7.5,5 \mathrm{mM}$ $\mathrm{MgCl}_{2}, 1 \times$ Roche complete protease inhibitor), and $250 \mu \mathrm{L}$ of this solution were put in each assay tube. Brain homogenates were incubated with various concentration of radiotracers (from 0.002 to $3 \mathrm{nM}$ ) for $1 \mathrm{~h}$ at room temperature before filtration using a cell harvester and rinsed 3 times with $1 \mathrm{~mL}$ of assay buffer. Filters were measured in a well counter (Wallac 2480; Perkin-Elmer) and decay-corrected to generate the dose-response curve. Nonspecific binding was assessed using the same experiment but replacing the assay buffer with a solution of $10 \mu \mathrm{mol}$ of MP-10 in assay buffer. Dissociation constants $\left(\mathrm{K}_{\mathrm{d}}\right)$ were estimated by nonlinear regression using GraphPad Prism 5 (GraphPad Inc.) to be 0.029 and $0.097 \mathrm{nM}$ for MNI-654 and MNI-659, respectively.

\section{Human Subjects}

The study protocol was reviewed and approved by the New England Institutional Review Board). Eleven healthy volunteers participated in this study $\left({ }^{18} \mathrm{~F}-\mathrm{MNI}-654\right.$ test-retest: 2 men, aged 50 and $53 \mathrm{y} ;{ }^{18} \mathrm{~F}-\mathrm{MNI}-659$ test-retest: 4 men and 1 woman, aged $36 \pm 7 \mathrm{y} ;{ }^{18} \mathrm{~F}-\mathrm{MNI}-$ 659 dosimetry: 2 men and 2 women, aged $42 \pm$ $5 \mathrm{y})$. All participating subjects provided written informed consent and underwent screening evaluation by a research physician including their first-in-human characterization, with the goal of developing a useful tool for striatal disease assessment and pharmaceutical development. To this end, test-retest and dosimetry studies were undertaken in healthy volunteers.

\section{MATERIALS AND METHODS}

\section{Radiochemistry}

${ }^{18} \mathrm{~F}-\mathrm{MNI}-654$ and ${ }^{18} \mathrm{~F}-\mathrm{MNI}-659$ were prepared by reaction of the corresponding tosylate precursor with ${ }^{18} \mathrm{~F}$ in the presence of potassium carbonate and Kryptofix-222 using a commercial synthesizer, TRACERlab FX-FN (GE Healthcare) (Fig. 1).

The resulting radiolabeled product was purified using a semipreparative high-performance liquid chromatography (HPLC) column (Eclipse XDB-C18, $5 \mu \mathrm{m}, 250 \times 9.4 \mathrm{~mm}$; Agilent) eluted with an acetonitrile/ water solution ( ${ }^{18} \mathrm{~F}-\mathrm{MNI} 659$ : 65/35; ${ }^{18} \mathrm{~F}-\mathrm{MNI} 654$ : $\left.40 / 60[\mathrm{v} / \mathrm{v}]\right)$ at a flow rate of $4 \mathrm{~mL} / \mathrm{min}$ and formulated in a physiologic solution (saline/ascorbic acid/polysorbate-80). For each radioligand, quality control showed a radiochemical purity above $99 \%$ and a specific activity exceeding $185 \mathrm{GBq} / \mu \mathrm{mol}(5 \mathrm{Ci} / \mu \mathrm{mol})$ for all the productions. The average radiochemical yield was $8.1 \% \pm 2.1 \%(n=14)$ for ${ }^{18} \mathrm{~F}-$ MNI-654 and $20.5 \% \pm 5.0 \%(n=50)$ for ${ }^{18} \mathrm{~F}-\mathrm{MNI}-659$.

\section{Pharmacologic Characterization}

A PDE10A saturation binding assay was performed for each radioligand on homogenized striata from 4 frozen male rat brains (SpragueDawley; Bioreclamation, Inc.) that were thawed in lysis buffer (21). After dissection, the striata were homogenized in $6 \mathrm{~mL}$ of lysis buffer (50 mM Tris-HCl, pH 7.5, $1.2 \mathrm{mM} \mathrm{MgCl} 2,0.1 \mathrm{mM}$ dithiothreitol, $10 \%$ sucrose, $1 \times$ Roche complete protease inhibitor) with a Polytron homogenizer at $0^{\circ} \mathrm{C}$. Cell membranes were separated by centrifugation at $10,000 \mathrm{~g}$ for $20 \mathrm{~min}$ at $4^{\circ} \mathrm{C}$. Two milliliters of the supernatant containing baseline clinical laboratory testing, a physical and neurologic evaluation, and cognitive assessment.

\section{Brain PET Studies}

Image Acquisition and Reconstruction. Three-dimensional brain PET images were acquired on a Siemens ECAT EXACT HR+ camera. Healthy control subjects were administered a single dose of ${ }^{18} \mathrm{~F}-\mathrm{MNI}-654$ $(171.3 \pm 23.3 \mathrm{MBq}$ [range, 136.9-187.2 MBq]; $0.67 \pm 0.38 \mu \mathrm{g}$ [range, $0.34-1.13 \mu \mathrm{g}])$ or ${ }^{18} \mathrm{~F}-\mathrm{MNI}-659$ (182.7 $\pm 8.5 \mathrm{MBq}$ [range, $163.5-195.0$ $\mathrm{MBq}$ ]; $1.08 \pm 0.90 \mu \mathrm{g}$ [range, $0.42-2.97 \mu \mathrm{g}$ ]) as a slow intravenous injection over $3 \mathrm{~min}$, followed by a $10-\mathrm{mL}$ saline flush. Images were acquired over $5.5 \mathrm{~h}$ for ${ }^{18} \mathrm{~F}-\mathrm{MNI}-654$ as 3 sessions of $90 \mathrm{~min}$. For ${ }^{18} \mathrm{~F}-$ MNI-659, subjects were imaged over $3.5 \mathrm{~h}$ as 2 sessions, with a first session of $90 \mathrm{~min}$ (first 2 subjects) or $120 \mathrm{~min}$ (last 3 subjects). The frames were of increasing duration from $30 \mathrm{~s}$ to $5 \mathrm{~min}$. All subjects were allowed $30 \mathrm{~min}$ of rest outside the camera between each imaging session. A transmission scan was obtained before each emission scan with an external ${ }^{68} \mathrm{Ge}$ rod source. Dynamic PET data were corrected for decay, attenuation, scatter, randoms, and dead time, and images were reconstructed using filtered backprojection with a gaussian filter $(5 \mathrm{~mm}$ in full width at half maximum).

MR Imaging. A structural 3-dimensional T1-weighted MR image was acquired for all subjects on a GE Signa Excite 1.5-T scanner (fast spoiled gradient echo; repetition time, $8.3 \mathrm{~ms}$; echo time, $4.0 \mathrm{~ms}$; flip angle, $15^{\circ}$ ) or on a Siemens Symphony 1.5-T scanner (magnetization-prepared rapid acquisition with gradient echo; repetition time, $2.0 \mathrm{~s}$; echo time, $3.9 \mathrm{~ms}$; flip angle, $15^{\circ}$ ).

Input Function Measurement. Blood samples were collected from the radial artery every $45 \mathrm{~s}$ until $6 \mathrm{~min}$ and then at $8,10,15,20,25,30$, $45,60,90,120,150,180$, and $210 \mathrm{~min}$ for ${ }^{18} \mathrm{~F}-\mathrm{MNI}-659$ and up to $330 \mathrm{~min}$ for ${ }^{18} \mathrm{~F}-\mathrm{MNI}-654$. Radioactivity in whole blood and plasma was measured for all samples in a $\gamma$ counter (Wallac 2480 Wizard; Perkin-Elmer), 


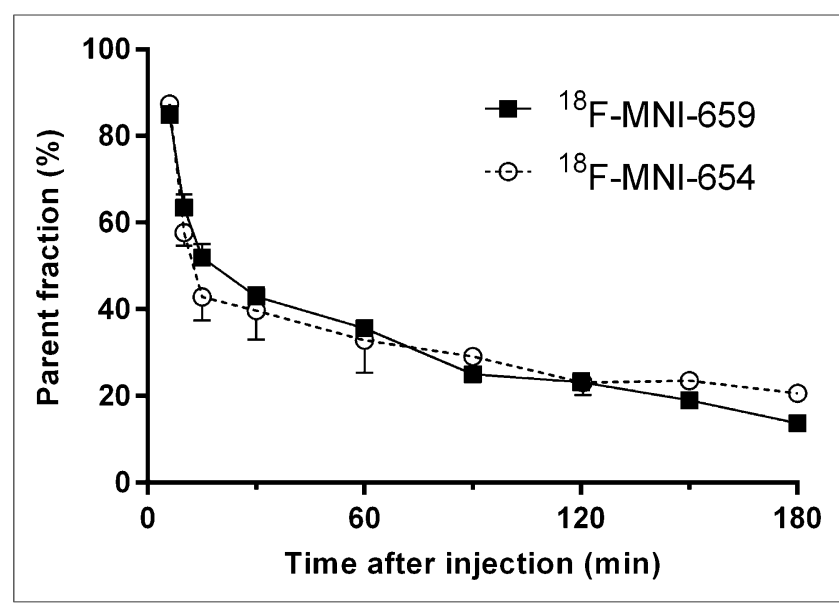

FIGURE 2. Average parent fraction profile in plasma after intravenous administration of ${ }^{18} \mathrm{~F}-\mathrm{MNI}-654(n=4)$ and ${ }^{18} \mathrm{~F}-\mathrm{MNI}-659(n=10)$. Error bars represent SD.

and in a subset radiometabolites were measured by reversed-phase HPLC on a Waters Nova-Pak C18 $(4.6 \times 250 \mathrm{~mm})$ at a flow rate of $1 \mathrm{~mL} / \mathrm{min}$. The mobile phase consisted of a mixture of methanol/water with $0.8 \%$ of triethylamine in an 80/20 ratio. Plasma samples were processed either by acetonitrile denaturation (samples up to $60 \mathrm{~min}$ ) or by liquid-liquid extraction with diethyl ether (after $60 \mathrm{~min}$ ). The plasma protein binding free fraction $\left(f_{\mathrm{p}}\right)$ was measured by ultrafiltration (Centrifree; Millipore).

Image Processing. Images were analyzed in PMOD 3.3 (PMOD Technologies). Images were frame-to-frame motion-corrected, realigned between sessions, merged, decay-corrected between sessions, and crosscalibrated with the well counter used for blood measurements. The initial PET images $(15 \mathrm{~min})$ were averaged and aligned onto the individual structural T1-weighted MR images. Both the MR imaging and the whole dynamic PET series were subsequently spatially normalized to the standard MNI (Montreal Neurologic Institute) space where a volume-of-interest template (comprising in particular the caudate, putamen, globus pallidus, cortical regions, thalamus, midbrain, brain stem, and cerebellum) was applied to extract the regional time-activity curves.

Kinetic Modeling. Time-activity curves were analyzed using standard 1-tissue- and 2-tissue-compartment models (1TCM and 2TCM) (27) as well as Logan graphical analysis (28) using the arterial plasma input function corrected for radiometabolites to derive the volume of distribution in each region. 1TCM and 2TCM assumed a whole-blood brain volume of $5 \%$. Two different binding potentials were estimated using the cerebellar cortex as a reference region: nondisplaceable binding potential $\left(\mathrm{BP}_{\mathrm{ND}}\right)=\mathrm{V}_{\mathrm{T}} / \mathrm{V}_{\mathrm{ND}}-1$ and plasma binding potential $\left(B P_{P}\right)=V_{T}-V_{N D}, V_{T}$ and $V_{N D}$ being the distribution volumes in the target and reference region, respectively (29).

The cerebellum has small levels of PDE10A in humans (6) and was shown to be a suitable reference region in baboons with ${ }^{11} \mathrm{C}-\mathrm{MP}-10$ (19). The free fraction $f_{\mathrm{p}}$ is low, and the measurements have a high variability. Therefore, $\mathrm{BP}_{\mathrm{F}}$ was not calculated, and $f_{\mathrm{p}}$ was not used to calculate $\mathrm{V}_{\mathrm{ND}}$ and $\mathrm{V}_{\mathrm{T}}$.

In addition to the plasma input models, the simplified reference tissue model (SRTM) (30) with the cerebellar cortex as a reference region was investigated to derive directly $\mathrm{BP}_{\mathrm{ND}}$. All kinetic analyses were performed using PMOD where 1TCM, 2TCM, and SRTM were estimated with a Levenberg-Marquardt optimizer.

Statistical Analysis. The goodness of fit was evaluated using the Akaike information criterion (AIC) (31) and model selection criterion (MSC) (32), where smaller AIC or larger MSC indicates a more appropriate model. SE (\% SE) was estimated from the covariance matrix diagonal elements and used to assess the parameter identifiability (33). Group data were expressed as mean \pm SD. Test-retest reproducibility was assessed by the variability as ABS(test - retest)/AVERAGE(test + retest), and reliability was assessed by the intraclass correlation coefficient (ICC), where an ICC of -1 denotes no reliability and +1 denotes maximum reliability.

\section{${ }^{18}$ F-MNI-659 Whole-Body Dosimetry Studies}

Whole-body PET imaging studies were performed on a Siemens $\mathrm{HR}+\mathrm{PET}$ camera to determine ${ }^{18} \mathrm{~F}-\mathrm{MNI}-659$ biodistribution and estimate radiation-absorbed doses. Four healthy controls ( 2 men, 2 women) received a bolus intravenous administration of ${ }^{18} \mathrm{~F}-\mathrm{MNI}-659$ (180.8 \pm 2.9 MBq [range, 176.6-182.8 MBq]; $0.87 \pm 0.17 \mu \mathrm{g}$ (range, 0.76-1.12 $\mu \mathrm{g}]$ ), immediately followed by a series of whole-body PET images consisting of 9 bed positions. Images were acquired over approximately $6 \mathrm{~h}$ in 3 scanning sessions, with subjects being allowed out of the camera for $30 \mathrm{~min}$ between sessions. The first session included 5 whole-body passes $(2 \times 60 \mathrm{~s}$ per bed position and $3 \times 120 \mathrm{~s}$ per bed position), and the last 2 sessions included 2 whole-body passes each $(2 \times 270$ s per bed position). A transmission scan was acquired before each imaging session with an external ${ }^{68} \mathrm{Ge}$ rod source. Urine was collected up to $8 \mathrm{~h}$ after radiotracer injection. PET data were corrected for attenuation, scatter, randoms, and dead time, and images were reconstructed using ordered-subset expectation maximization (4 iterations, 16 subsets). Source organs were identified, and non-decay-corrected time-activity curves were generated (expressed as percentage injected dose). Radiationabsorbed dose and effective dose (weighted average using ICRP-60 tissue-weighting factors (34)) were estimated with the OLINDA/EXM 1.0 software package. ICRP-30 (35) gastrointestinal tract kinetics were used with the assumption that activity entered the bowel through the hepatobiliary system; an intestinal decay-corrected time-activity curve was used for estimation of the fraction of activity entering the intestine. The adult male and female models, adjusted to each individual body mass, were assumed for the male and female subjects, respectively.

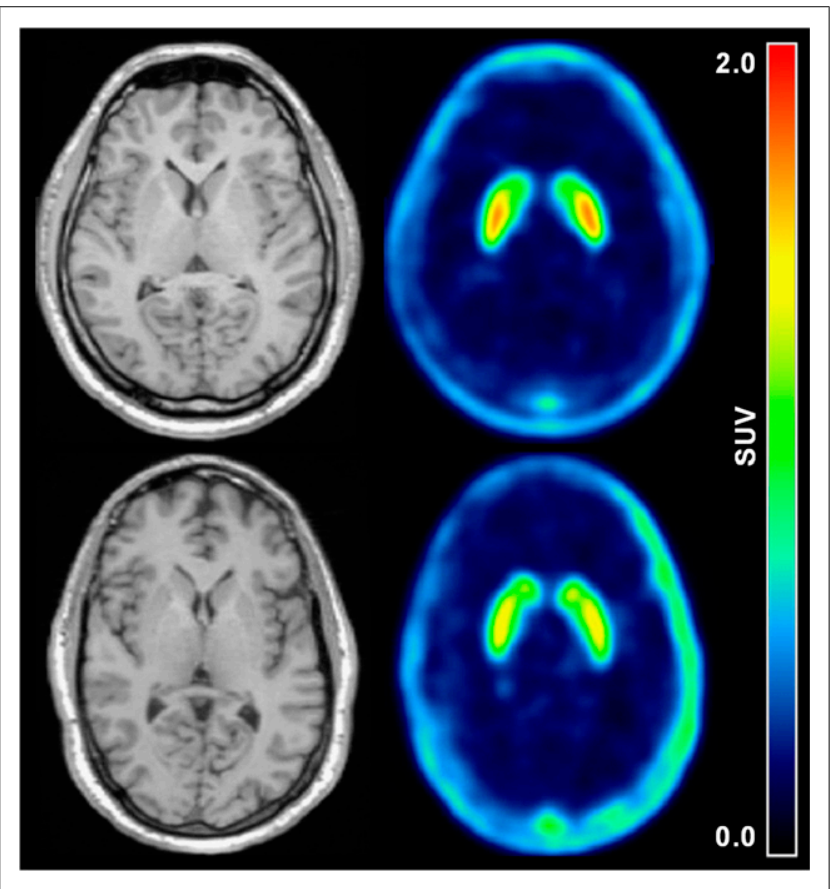

FIGURE 3. Transverse MR and average PET images (30-90 min) for ${ }^{18} \mathrm{~F}-\mathrm{MNI}-659$ (top) and ${ }^{18} \mathrm{~F}-\mathrm{MNI}-654$ (bottom) for 2 healthy subjects. SUV = standardized uptake value. 


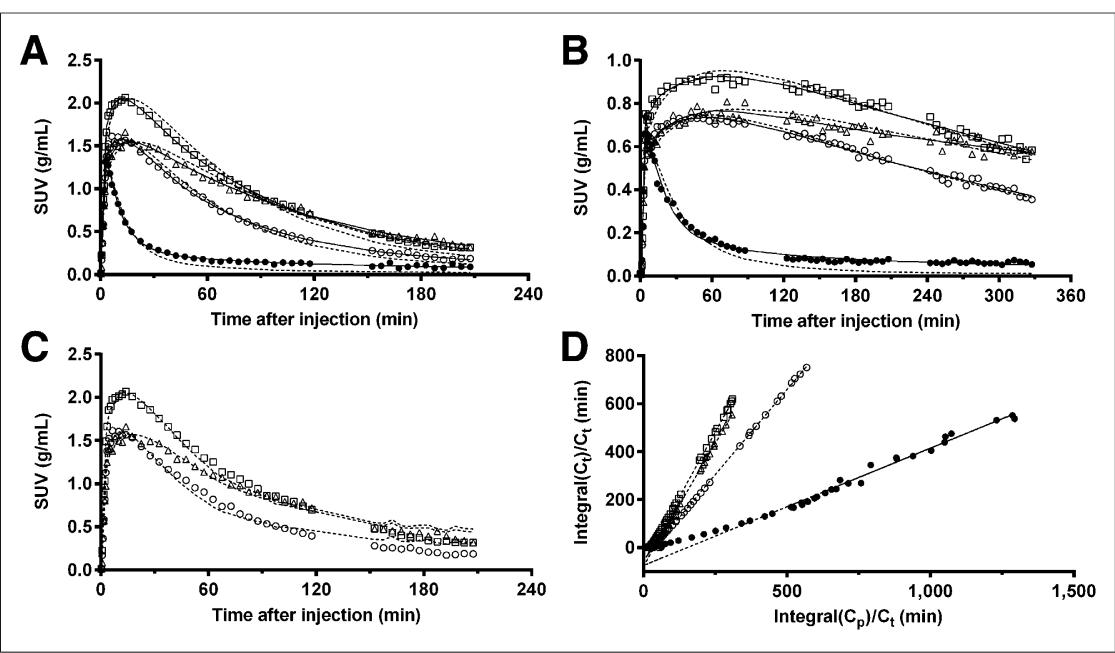

FIGURE 4. (A) ${ }^{18} \mathrm{~F}-\mathrm{MNI}-659$ time-activity curves in caudate, putamen, globus pallidus, and cerebellum showing 1TCM (dashed line) and 2TCM fits (solid line). (B) ${ }^{18} \mathrm{~F}-\mathrm{MNI}-654$ time-activity curves in caudate, putamen, globus pallidus, and cerebellum showing 1TCM (dashed line) and 2TCM fits (solid line). (C) ${ }^{18} \mathrm{~F}-\mathrm{MNI}-659$ time-activity curves in caudate, putamen, and globus pallidus showing SRTM fits (dashed line). (D) ${ }^{18} \mathrm{~F}-\mathrm{MNI}-659$ Logan plots in caudate, putamen, globus pallidus, and cerebellum showing linear regression (dashed line). $O=$ caudate; $\square=$ putamen; $\Delta=$ globus pallidus; $\bullet=$ cerebellum. $C_{p}=$ plasma activity concentration; $C_{t}=$ tissue activity concentration; SUV $=$ standardized uptake value.

\section{RESULTS}

\section{Plasma Analysis}

HPLC analysis of arterial plasma showed that ${ }^{18} \mathrm{~F}-\mathrm{MNI}-654$ and ${ }^{18}$ F-MNI-659 were moderately metabolized with a similar profile, with about $20 \%$ of intact parent remaining at $120 \mathrm{~min}$ after injection for both (Fig. 2). $f_{\mathrm{p}}$ was measured by ultrafiltration as $0.5 \%-1.3 \%$ $(n=4)$ for ${ }^{18} \mathrm{~F}-\mathrm{MNI}-654$ and $0.1 \%-0.7 \%(n=10)$ for ${ }^{18} \mathrm{~F}-\mathrm{MNI}-$ 659 but was not used to calculate the distribution volumes. For both ${ }^{18} \mathrm{~F}-\mathrm{MNI}-654$ and ${ }^{18} \mathrm{~F}-\mathrm{MNI}-659$, radiometabolites were more polar than the parent compounds and are therefore not expected to penetrate the blood-brain barrier.

\section{Brain Distribution and Kinetics}

Representative average PET images from 30 to 90 min of acquisition of ${ }^{18} \mathrm{~F}-\mathrm{MNI}-654$ and ${ }^{18} \mathrm{~F}-\mathrm{MNI}-659$ show high uptake in the caudate, putamen, and globus pallidus, regions rich in PDE10A (Fig. 3). Representative time-activity curves of selected regions are presented in Figure 4. ${ }^{18} \mathrm{~F}-\mathrm{MNI}-654$ and ${ }^{18} \mathrm{~F}-\mathrm{MNI}-659$ readily entered the human brain, with a peak uptake of $0.7-$ 1.0 standardized uptake value around 60 $80 \mathrm{~min}$ after injection for ${ }^{18} \mathrm{~F}-\mathrm{MNI}-654$ and of 1.5-2.5 standardized uptake value around 10-20 min after injection for ${ }^{18} \mathrm{~F}-\mathrm{MNI}-659$ in the caudate, putamen, and globus pallidus and a much faster washout in all other brain regions, in particular in the cerebellum (peak uptake within 5 min of injection), consistent with the much lower PDE10A density in these regions (6). ${ }^{18} \mathrm{~F}-\mathrm{MNI}-659$ displayed much faster kinetics than ${ }^{18} \mathrm{~F}-\mathrm{MNI}-654$, with a significant washout over $3.5 \mathrm{~h}$.

\section{${ }^{18}$ F-MNI-654 Kinetic Modeling}

2TCM provided better fits of ${ }^{18} \mathrm{~F}-\mathrm{MNI}-$ 654 data than 1TCM based on AIC and MSC (Fig. 4), in particular in the cerebellum where 1TCM did not properly describe the late part of the time-activity curve. The Logan plot $\left(\mathrm{t}^{*}=30 \mathrm{~min}\right)$ provided $\mathrm{V}_{\mathrm{T}}$ estimates in good agreement with $2 \mathrm{TCM}$ $\left(r^{2}>0.96\right)$ although lower by about $10 \%$. SRTM failed to describe accurately the initial part of the curves but described appropriately the washout phase at later time points. Logan and SRTM $\mathrm{BP}_{\mathrm{ND}}$ correlated well with $2 \mathrm{TCM}$ estimates $\left(r^{2}>0.96\right)$ but were lower by about $10 \%-20 \%$ and $30 \%-$ $40 \%$, respectively. $2 \mathrm{TCM} \mathrm{V}_{\mathrm{T}}$ and $\mathrm{BP}_{\mathrm{ND}}$ in the striatum were estimated to be $4.5 \pm 0.8$ and $7.0 \pm 1.5$, respectively. Test-retest variability was poor ( $20 \%$ for $\mathrm{V}_{\mathrm{T}}, 30 \%-40 \%$ for $\left.\mathrm{BP}_{\mathrm{ND}}\right)$, and reducing the acquisition duration below $3 \mathrm{~h}$ led to convergence issues in some regions, in particular the globus pallidus. Because of the poor imaging characteristics of this compound, no further analysis was done with ${ }^{18} \mathrm{~F}-\mathrm{MNI}-654$, and results in the remainder of this report refer only to ${ }^{18} \mathrm{~F}-\mathrm{MNI}-659$.

\section{${ }^{18}$ F-MNI-659 Kinetic Modeling}

2TCM is again the preferred configuration for ${ }^{18} \mathrm{~F}-\mathrm{MNI}-659$ data, compared with 1TCM, with smaller AIC and higher MSC in all regions where 1TCM fits undershot the late part of the timeactivity curves, particularly for the cerebellum. Typical 1TCM, 2TCM, and SRTM fits and Logan plots ( $\left.\mathrm{t}^{*}=30 \mathrm{~min}\right)$ are provided in Figure 4. SRTM did not fit perfectly the data, in particular the late part of the curves, but the fits improved for shorter acquisitions. A summary of the modeling parameters for 90 and $210 \mathrm{~min}$ of data is given in Supplemental Table 1 (supplemental materials are available at http:// jnm.snmjournals.org) for all 4 methods. Overall, $\mathrm{V}_{\mathrm{T}}$ had a low error around $2 \%$ in the high-uptake regions for both 2TCM and 1TCM, which slightly increased when using $90 \mathrm{~min}$ of data, in particular in the globus pallidus. The error was larger in the cerebellum, in particular for 2TCM $(13.3 \% \pm$ $7.5 \%$ for $210 \mathrm{~min}$ reduced to $7.8 \% \pm 7.4 \%$ for $90 \mathrm{~min}$ of data). $K_{1}$ also had a low error around $2 \%-3 \%$ for the high-uptake regions, slightly worse in the cerebellum $(5 \%-6 \%)$. The intersubject $\mathrm{V}_{\mathrm{T}}$ variability 
TABLE 1

${ }^{18} \mathrm{~F}-\mathrm{MNI}-659 \mathrm{~V}_{\mathrm{T}}$ Test-Retest for 2TCM, 1TCM, and Logan for 90-Minute Acquisitions

\begin{tabular}{|c|c|c|c|c|c|c|c|c|c|}
\hline \multirow[b]{2}{*}{ Model } & \multirow[b]{2}{*}{ Parameter } & \multicolumn{2}{|c|}{ Caudate } & \multicolumn{2}{|c|}{ Putamen } & \multicolumn{2}{|c|}{ Globus pallidus } & \multicolumn{2}{|c|}{ Cerebellum } \\
\hline & & Scan 1 & Scan 2 & Scan 1 & Scan 2 & Scan 1 & Scan 2 & Scan 1 & Scan 2 \\
\hline \multirow[t]{3}{*}{$2 \mathrm{TCM}$} & $\mathrm{V}_{\mathrm{T}}$ & $1.74 \pm 0.63$ & $1.64 \pm 0.47$ & $2.81 \pm 0.95$ & $2.57 \pm 0.65$ & $2.95 \pm 0.99$ & $2.67 \pm 0.75$ & $0.49 \pm 0.16$ & $0.47 \pm 0.10$ \\
\hline & Variability* & $31 \% \pm 11 \%$ & & $31 \% \pm 9 \%$ & & $28 \% \pm 11 \%$ & & $29 \% \pm 10 \%$ & \\
\hline & $\mathrm{ICC}^{*}$ & 0.55 & & 0.42 & & 0.57 & & 0.40 & \\
\hline \multirow[t]{3}{*}{$1 \mathrm{TCM}$} & $\mathrm{V}_{\mathrm{T}}$ & $1.66 \pm 0.60$ & $1.57 \pm 0.48$ & $2.61 \pm 0.88$ & $2.40 \pm 0.69$ & $2.62 \pm 0.91$ & $2.38 \pm 0.74$ & $0.36 \pm 0.13$ & $0.35 \pm 0.09$ \\
\hline & Variability* & $31 \% \pm 11 \%$ & & $33 \% \pm 10 \%$ & & $33 \% \pm 8 \%$ & & $34 \% \pm 10 \%$ & \\
\hline & $\mathrm{ICC}^{*}$ & 0.55 & & 0.45 & & 0.52 & & 0.41 & \\
\hline \multirow[t]{3}{*}{ Logan } & $\mathrm{V}_{\mathrm{T}}$ & $1.71 \pm 0.58$ & $1.64 \pm 0.49$ & $2.74 \pm 0.87$ & $2.54 \pm 0.72$ & $2.80 \pm 0.90$ & $2.55 \pm 0.80$ & $0.56 \pm 0.17$ & $0.55 \pm 0.16$ \\
\hline & Variability* & $30 \% \pm 13 \%$ & & $32 \% \pm 11 \%$ & & $32 \% \pm 10 \%$ & & $30 \% \pm 18 \%$ & \\
\hline & $\mathrm{ICC}^{\star}$ & 0.53 & & 0.42 & & 0.53 & & 0.43 & \\
\hline
\end{tabular}

*Variability and ICC are for both scan 1 and scan 2.

$n=5$, mean \pm SD.

was around $30 \%$ for all brain regions investigated for $2 \mathrm{TCM}$, 1TCM, and Logan. A similar intersubject variability of $30 \%$ was measured for $K_{1}$ in all regions for both 2TCM and 1TCM.

Model Comparison. Correlations of $\mathrm{V}_{\mathrm{T}}, \mathrm{BP}_{\mathrm{P}}$, and $\mathrm{BP}_{\mathrm{ND}}$ obtained with 2TCM, 1TCM, Logan, or SRTM were done using 90-min estimates (Supplemental Fig. 1 for correlations of 210-min estimates). For $\mathrm{V}_{\mathrm{T}}, 2 \mathrm{TCM}$ and 1TCM correlated well with Logan, close to the line of identity, with an $r^{2}$ greater than 0.99 and a slope close to 1.0 (Fig. 5). Regions with low $\mathrm{V}_{\mathrm{T}}$ (cerebellum) were, however, underestimated for 1TCM, compared with Logan $(-35 \%)$. For $\mathrm{BP}_{\mathrm{P}}$, there was again a good agreement of $2 \mathrm{TCM}$ and $1 \mathrm{TCM}$ versus Logan, with an $r^{2}$ greater than 0.99 and a slope close to 1.0. 2TCM overestimated $\mathrm{BP}_{\mathrm{P}}$ by $10 \%$, compared with Logan. For $\mathrm{BP}_{\mathrm{ND}}$, SRTM correlated well with Logan, with an $r^{2}$ greater than 0.98 and an overestimation of less than 10\%. 2TCM overestimated $\mathrm{BP}_{\mathrm{ND}}$ by $20 \%-30 \%$, and $1 \mathrm{TCM}$ clearly overestimated $\mathrm{BP}_{\mathrm{ND}}$, compared with Logan $(60 \%-70 \%)$, due to the lower $1 \mathrm{TCM} \mathrm{V}_{\mathrm{T}}$ estimate in the cerebellum.
Test-Retest. Results for $\mathrm{VT}, \mathrm{BP}_{\mathrm{p}}$, and $\mathrm{BP}_{\mathrm{ND}}$ are summarized in Table 1, 2, and 3 for $90 \mathrm{~min}$ of data (Supplemental Tables 2, 3, and 4 for acquisitions of $210 \mathrm{~min}$ ). $\mathrm{BP}_{\mathrm{ND}}$ shows test-retest of around $10 \%-20 \%$ for 2 TCM and below $10 \%$ for all other methods. Both $\mathrm{V}_{\mathrm{T}}$ and $\mathrm{BP}_{\mathrm{P}}$ showed moderate reproducibility around $30 \%$. ICC of $\mathrm{BP}_{\mathrm{ND}}$ was good, above 0.8 for all methods except 1TCM (0.4-0.8 for $90 \mathrm{~min}$ ). For $\mathrm{V}_{\mathrm{T}}$, the ICC was around $0.4-0.6$ for $2 \mathrm{TCM}$, 1TCM, and Logan in all regions, and for $\mathrm{BP}_{\mathrm{P}}$, the ICC was slightly better around $0.5-0.7$. The average of the estimates for the retest studies were all within $10 \%$ of the test studies.

\section{${ }^{18} \mathrm{~F}-\mathrm{MNI}-659$ Whole-Body Dosimetry}

${ }^{18} \mathrm{~F}-\mathrm{MNI}-659$ whole-body distribution over time is shown in Figure 6. The 7 organs identified as source organs for the radiation dosimetry calculation were the brain, heart, liver, gallbladder, urinary bladder, kidneys, and intestines. The elimination of the radiotracer was primarily via the hepatobiliary route, with the gallbladder wall having the highest organ dose. The radioactivity present in urine

TABLE 2

${ }^{18} \mathrm{~F}-\mathrm{MNI}-659 \mathrm{BP}_{\mathrm{P}}$ Test-Retest for 2TCM, 1TCM, and Logan for 90-Minute Acquisitions

\begin{tabular}{|c|c|c|c|c|c|c|c|}
\hline \multirow[b]{2}{*}{ Model } & \multirow[b]{2}{*}{ Parameter } & \multicolumn{2}{|c|}{ Caudate } & \multicolumn{2}{|c|}{ Putamen } & \multicolumn{2}{|c|}{ Globus pallidus } \\
\hline & & Scan 1 & Scan 2 & Scan 1 & Scan 2 & Scan 1 & Scan 2 \\
\hline \multirow[t]{3}{*}{ 2TCM } & $\mathrm{BP}_{\mathrm{P}}$ & $1.24 \pm 0.51$ & $1.17 \pm 0.42$ & $2.31 \pm 0.82$ & $2.10 \pm 0.58$ & $2.45 \pm 0.85$ & $2.20 \pm 0.66$ \\
\hline & Variability* & $33 \% \pm 15 \%$ & & $32 \% \pm 11 \%$ & & $28 \% \pm 12 \%$ & \\
\hline & $\mathrm{ICC}^{*}$ & 0.67 & & 0.48 & & 0.62 & \\
\hline \multirow[t]{3}{*}{$1 \mathrm{TCM}$} & $\mathrm{BP}_{\mathrm{P}}$ & $1.30 \pm 0.48$ & $1.22 \pm 0.39$ & $2.25 \pm 0.76$ & $2.05 \pm 0.60$ & $2.26 \pm 0.79$ & $2.03 \pm 0.64$ \\
\hline & Variability* & $30 \% \pm 12 \%$ & & $33 \% \pm 11 \%$ & & $33 \% \pm 9 \%$ & \\
\hline & $\mathrm{ICC}^{*}$ & 0.61 & & 0.46 & & 0.54 & \\
\hline \multirow[t]{3}{*}{ Logan } & $\mathrm{BP}_{\mathrm{P}}$ & $1.16 \pm 0.44$ & $1.09 \pm 0.39$ & $2.19 \pm 0.72$ & $1.99 \pm 0.61$ & $2.24 \pm 0.75$ & $2.00 \pm 0.67$ \\
\hline & Variability* & $30 \% \pm 12 \%$ & & $33 \% \pm 10 \%$ & & $32 \% \pm 10 \%$ & \\
\hline & $\mathrm{ICC}^{\star}$ & 0.62 & & 0.45 & & 0.55 & \\
\hline
\end{tabular}

*Variability and ICC are for both scan 1 and scan 2.

$n=5$, mean \pm SD. 
TABLE 3

${ }^{18} \mathrm{~F}-\mathrm{MNI}-659 \mathrm{BP}_{\mathrm{ND}}$ Test-Retest for 2TCM, 1TCM, Logan, and SRTM for 90-Minute Acquisitions

\begin{tabular}{|c|c|c|c|c|c|c|c|}
\hline \multirow[b]{2}{*}{ Model } & \multirow[b]{2}{*}{ Parameter } & \multicolumn{2}{|c|}{ Caudate } & \multicolumn{2}{|c|}{ Putamen } & \multicolumn{2}{|c|}{ Globus pallidus } \\
\hline & & Scan 1 & Scan 2 & Scan 1 & Scan 2 & Scan 1 & Scan 2 \\
\hline \multirow[t]{3}{*}{ 2TCM } & $\mathrm{BP}_{\mathrm{ND}}$ & $2.58 \pm 1.04$ & $2.52 \pm 0.75$ & $4.81 \pm 1.57$ & $4.49 \pm 0.97$ & $5.09 \pm 1.49$ & $4.66 \pm 0.81$ \\
\hline & Variability* & $13 \% \pm 8 \%$ & & $11 \% \pm 7 \%$ & & $10 \% \pm 9 \%$ & \\
\hline & $\mathrm{ICC}^{*}$ & 0.94 & & 0.87 & & 0.77 & \\
\hline \multirow[t]{3}{*}{$1 \mathrm{TCM}$} & $\mathrm{BP}_{\mathrm{ND}}$ & $3.61 \pm 0.86$ & $3.45 \pm 0.55$ & $6.33 \pm 1.28$ & $5.82 \pm 0.65$ & $6.33 \pm 0.97$ & $5.70 \pm 0.48$ \\
\hline & Variability* & $6 \% \pm 7 \%$ & & $9 \% \pm 9 \%$ & & $10 \% \pm 9 \%$ & \\
\hline & $\mathrm{ICC}^{*}$ & 0.86 & & 0.68 & & 0.43 & \\
\hline \multirow[t]{3}{*}{ Logan } & $\mathrm{BP}_{\mathrm{ND}}$ & $2.06 \pm 0.55$ & $2.04 \pm 0.61$ & $3.93 \pm 0.78$ & $3.71 \pm 0.85$ & $4.03 \pm 0.67$ & $3.67 \pm 0.67$ \\
\hline & Variability ${ }^{*}$ & $8 \% \pm 6 \%$ & & $8 \% \pm 10 \%$ & & $11 \% \pm 8 \%$ & \\
\hline & $\mathrm{ICC}^{*}$ & 0.96 & & 0.88 & & 0.76 & \\
\hline \multirow[t]{3}{*}{ SRTM } & $\mathrm{BP}_{\mathrm{ND}}$ & $2.13 \pm 0.53$ & $2.13 \pm 0.53$ & $3.84 \pm 0.70$ & $3.66 \pm 0.73$ & $3.65 \pm 0.49$ & $3.41 \pm 0.65$ \\
\hline & Variability* & $7 \% \pm 5 \%$ & & $5 \% \pm 7 \%$ & & $8 \% \pm 7 \%$ & \\
\hline & $\mathrm{ICC}^{*}$ & 0.95 & & 0.92 & & 0.84 & \\
\hline
\end{tabular}

*Variability and ICC are for both scan 1 and scan 2.

$n=5$, mean \pm SD.

was determined to be less than $10 \%$ of the injected dose. The average absorbed organ doses and effective dose across the 4 subjects are given in Table 4. The average effective dose was estimated to be $0.024 \pm 0.007 \mathrm{mSv} / \mathrm{MBq}$. This radiation exposure was similar to other ${ }^{18} \mathrm{~F}$-labeled tracers $\left({ }^{18} \mathrm{~F}\right.$-FDG is $\left.0.019 \mathrm{mSv} / \mathrm{MBq}\right)$ and would allow several scans to be obtained in the same subject per year with a $180-\mathrm{MBq}$ injected dose.

\section{DISCUSSION}

The primary aim of this study was to evaluate 2 potential PET radioligands for in vivo imaging of the PDE10A enzyme in the human brain. ${ }^{18} \mathrm{~F}-\mathrm{MNI}-654$ and ${ }^{18} \mathrm{~F}-\mathrm{MNI}-659$ readily enter the brain, with an uptake distribution in agreement with the known distribution of PDE10A in the human brain (caudate $\sim$ putamen $\sim$ globus pallidus $>>$ cortex, cerebellum). ${ }^{18}$ F-MNI-654 and ${ }^{18}$ F-MNI-659 also had a similar parent fraction profile over time. However, ${ }^{18} \mathrm{~F}-$ MNI-654 kinetics proved to be too slow, requiring long acquisitions of at least $180 \mathrm{~min}$ for robust estimates, with a poor reproducibility for both $\mathrm{V}_{\mathrm{T}}$ and $\mathrm{BP}_{\mathrm{ND}}$.

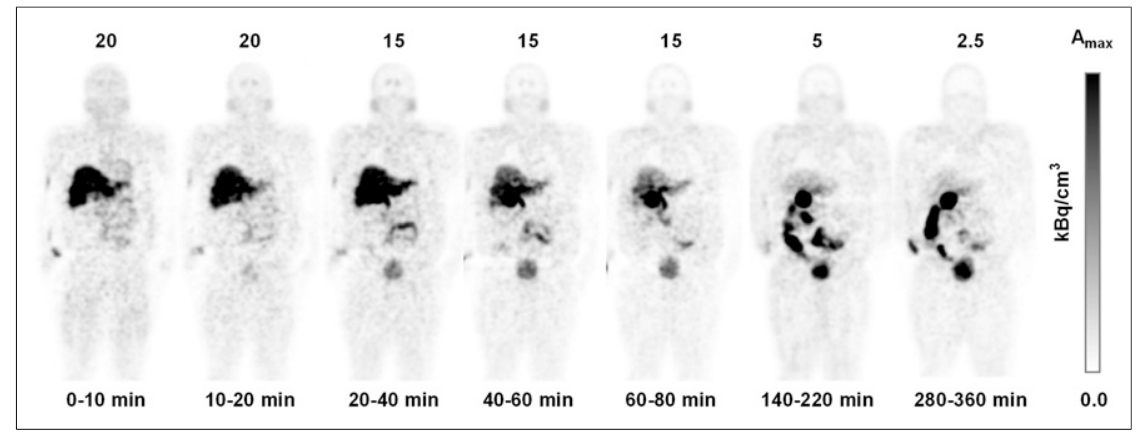

FIGURE 6. Coronal PET images showing temporal distribution over $6 \mathrm{~h}$ of ${ }^{18} \mathrm{~F}-\mathrm{MNI}-659$. Same color scale is used but with different maximum activity (given above images) to better visualize relative distribution. Amax $=$ maximum activity concentration.
${ }^{18}$ F-MNI-659-measured plasma-free fraction was low $(\sim 1 \%)$, and liquid-liquid extraction was used to improve the counting statistics of the HPLC samples beyond $60 \mathrm{~min}$ although acetonitrile denaturation led to sufficient counts up to $90 \mathrm{~min}$. In addition, $\mathrm{V}_{\mathrm{T}}$ intrasubject variability was similar to $\mathrm{V}_{\mathrm{T}}$ and $K_{1}$ intersubject variability, all around $30 \%$, suggesting that the observed $\mathrm{V}_{\mathrm{T}}$ variability is probably mainly driven by measurement errors of the parent plasma input function. This finding is further supported by a $\mathrm{BP}_{\mathrm{ND}}$ testretest, which is below approximately $10 \%$.

Although 2TCM was the favored model, 2TCM and 1TCM gave $\mathrm{V}_{\mathrm{T}}$ estimates within $10 \%$ in the PDE10A-rich regions. However, in the cerebellum, 2TCM was clearly favored and gave estimates higher by $25 \%$ and $50 \%$ for scans of 90 and $210 \mathrm{~min}$, compared with 1TCM, respectively. On the other hand, 1TCM although biased was the most robust method against the scan duration, with variability and ICC similar to $2 \mathrm{TCM}$ and Logan for $\mathrm{V}_{\mathrm{T}}$ and good results for $\mathrm{BP}_{\mathrm{P}}$ and $\mathrm{BP}_{\mathrm{ND}}$ as well.

In the cerebellum and the other low-uptake regions (cortex, thalamus), 2TCM gave a small $k_{4}$ rate constant (29). However, reversible 2TCM was still favored against an irreversible model based on AIC and MSC (data not shown), with in any case a clear reversibility of the tracer in the basal ganglia. The need of 2 compartments to describe the kinetics in a reference region is usually due to low specific binding (although in humans, PDE10A levels in the cerebellum are small (6)), heterogeneity (gray and white matter), or a slow transfer rate between free and nonspecifically bound tracer. Investigation of higher-order compartment models showed that a third compartment (reversible or irreversible) improved the AIC and MSC (though marginally), and spectral analysis (36) revealed a slow component. The nature of this slow component is unclear at this stage but could 
TABLE 4

Mean Radiation-Absorbed Dose as Well as Effective Dose (mSv/MBq)

\begin{tabular}{llc}
\hline \multicolumn{1}{c}{ Target organ } & Mean & SD \\
\hline Adrenals & $1.49 \mathrm{E}-02$ & $2.99 \mathrm{E}-03$ \\
\hline Brain & $3.32 \mathrm{E}-03$ & $6.45 \mathrm{E}-04$ \\
\hline Breasts & $7.12 \mathrm{E}-03$ & $1.84 \mathrm{E}-03$ \\
\hline Gallbladder wall & $5.05 \mathrm{E}-01$ & $3.62 \mathrm{E}-01$ \\
\hline Lower large intestinal wall & $5.94 \mathrm{E}-02$ & $2.07 \mathrm{E}-02$ \\
\hline Small intestine & $1.60 \mathrm{E}-01$ & $6.56 \mathrm{E}-02$ \\
\hline Stomach wall & $1.75 \mathrm{E}-02$ & $4.11 \mathrm{E}-03$ \\
\hline Upper large intestinal wall & $1.77 \mathrm{E}-01$ & $7.18 \mathrm{E}-02$ \\
\hline Heart wall & $1.20 \mathrm{E}-02$ & $2.18 \mathrm{E}-03$ \\
\hline Kidneys & $1.90 \mathrm{E}-02$ & $4.92 \mathrm{E}-03$ \\
\hline Liver & $4.08 \mathrm{E}-02$ & $1.98 \mathrm{E}-02$ \\
\hline Lungs & $9.40 \mathrm{E}-03$ & $2.09 \mathrm{E}-03$ \\
\hline Muscle & $1.14 \mathrm{E}-02$ & $2.17 \mathrm{E}-03$ \\
\hline Ovaries & $3.30 \mathrm{E}-02$ & $1.08 \mathrm{E}-02$ \\
\hline Pancreas & $1.92 \mathrm{E}-02$ & $4.38 \mathrm{E}-03$ \\
\hline Red marrow & $1.24 \mathrm{E}-02$ & $2.52 \mathrm{E}-03$ \\
\hline Osteogenic cells & $1.31 \mathrm{E}-02$ & $3.88 \mathrm{E}-03$ \\
\hline Skin & $7.10 \mathrm{E}-03$ & $1.68 \mathrm{E}-03$ \\
\hline Spleen & $1.22 \mathrm{E}-02$ & $2.60 \mathrm{E}-03$ \\
\hline Testes & $7.09 \mathrm{E}-03$ & $5.66 \mathrm{E}-04$ \\
\hline Thymus & $8.30 \mathrm{E}-03$ & $2.44 \mathrm{E}-03$ \\
\hline Thyroid & $7.25 \mathrm{E}-03$ & $2.32 \mathrm{E}-03$ \\
\hline Urinary bladder & $2.97 \mathrm{E}-02$ & $7.15 \mathrm{E}-03$ \\
\hline Uterus & $2.71 \mathrm{E}-02$ & $7.61 \mathrm{E}-03$ \\
\hline Total body & $1.41 \mathrm{E}-02$ & $2.79 \mathrm{E}-03$ \\
\hline Effective dose $(34)$ & $2.41 \mathrm{E}-02$ & $7.00 \mathrm{E}-03$ \\
\hline & & \\
\hline
\end{tabular}

explain, at least partly, the difficulties in fitting the data in the lowuptake regions with $2 \mathrm{TCM}$.

For $\mathrm{BP}_{\mathrm{ND}}$, SRTM gave the best results, with variability less than $10 \%$ and ICC greater than 0.9 . Variability was moderate $(\sim 30 \%)$ for $\mathrm{V}_{\mathrm{T}}$ and $\mathrm{BP}_{\mathrm{P}}$ for all methods investigated. There was good agreement between Logan and SRTM, giving more confidence that noninvasive modeling with SRTM is appropriate to derive $\mathrm{BP}_{\mathrm{ND}}$ despite the discrepancy observed for 1TCM and 2TCM due to their difficulties in describing the uptake in the cerebellum. In addition, SRTM $\mathrm{BP}_{\mathrm{ND}}$ estimates were robust against the acquisition length, with values for $210 \mathrm{~min}$ of data within $8 \%$ of those derived with $90 \mathrm{~min}$ of data.

Further work is needed to fully validate the use of the cerebellum as a reference region for quantification of the PDE10A signal with ${ }^{18} \mathrm{~F}-\mathrm{MNI}-659$ in the human brain or at least estimate the bias or level of specific binding in that region, compared with the nonspecific and free signal (37-39). Moreover, it would be useful to further assess the bias due to SRTM assumption violation and sensitivity due to changes in the cerebral blood flow using a simulated dataset $(37,40)$.

\section{CONCLUSION}

We reported here the PET imaging of PDE10A in the human brain with 2 novel ${ }^{18} \mathrm{~F}$ tracers. ${ }^{18} \mathrm{~F}-\mathrm{MNI}-654$ kinetics were slow, and long acquisitions would be necessary with this radiotracer. Noninvasive quantification of ${ }^{18} \mathrm{~F}-\mathrm{MNI}-659$ with SRTM using the cerebellum as a reference is possible, and SRTM $\mathrm{BP}_{\mathrm{ND}}$ estimates with ${ }^{18} \mathrm{~F}$ MNI-659 proved to be robust. In addition, ${ }^{18} \mathrm{~F}-\mathrm{MNI}-659$ kinetics are fast enough for a good estimate of $\mathrm{BP}_{\mathrm{ND}}$ with 90-min acquisitions, with values around 3.0 in the basal ganglia. Finally, ${ }^{18} \mathrm{~F}-$ MNI-659 dosimetry is favorable with an effective dose estimated around $0.024 \mathrm{mSv} / \mathrm{MBq}$, consistent with values reported for other PET radiotracers currently used in humans.

\section{DISCLOSURE}

The costs of publication of this article were defrayed in part by the payment of page charges. Therefore, and solely to indicate this fact, this article is hereby marked "advertisement" in accordance with 18 USC section 1734 . No potential conflict of interest relevant to this article was reported.

\section{REFERENCES}

1. Reneerkens OA, Rutten K, Steinbusch HW, Blokland A, Prickaerts J. Selective phosphodiesterase inhibitors: a promising target for cognition enhancement. Psychopharmacology (Berl). 2009;202:419-443.

2. Conti M, Beavo J. Biochemistry and physiology of cyclic nucleotide phosphodiesterases: essential components in cyclic nucleotide signaling. Аnnu Rev Biochem. 2007;76:481-511.

3. Francis SH, Blount MA, Corbin JD. Mammalian cyclic nucleotide phosphodiesterases: molecular mechanisms and physiological functions. Physiol Rev. 2011;91: 651-690.

4. Menniti FS, Faraci WS, Schmidt CJ. Phosphodiesterases in the CNS: targets for drug development. Nat Rev Drug Discov. 2006;5:660-670.

5. Xie Z, Adamowicz WO, Eldred WD, et al. Cellular and subcellular localization of PDE10A, a striatum-enriched phosphodiesterase. Neuroscience. 2006;139:597-607.

6. Lakics V, Karran EH, Boess FG. Quantitative comparison of phosphodiesterase mRNA distribution in human brain and peripheral tissues. Neuropharmacology. 2010;59:367-374.

7. Fujishige K, Kotera J, Michibata H, et al. Cloning and characterization of a novel human phosphodiesterase that hydrolyzes both cAMP and cGMP (PDE10A). J Biol Chem. 1999;274:18438-18445.

8. Siuciak JA, McCarthy SA, Chapin DS, et al. Genetic deletion of the striatumenriched phosphodiesterase PDE10A: evidence for altered striatal function. $\mathrm{Neu}$ ropharmacology. 2006;51:374-385.

9. Hebb AL, Robertson HA. Role of phosphodiesterases in neurological and psychiatric disease. Curr Opin Pharmacol. 2007;7:86-92.

10. Giorgi M, Melchiorri G, Nuccetelli V, et al. PDE10A and PDE10A-dependent cAMP catabolism are dysregulated oppositely in striatum and nucleus accumbens after lesion of midbrain dopamine neurons in rat: a key step in parkinsonism physiopathology. Neurobiol Dis. 2011;43:293-303.

11. Kleiman RJ, Kimmel LH, Bove SE, et al. Chronic suppression of phosphodiesterase $10 \mathrm{~A}$ alters striatal expression of genes responsible for neurotransmitter synthesis, neurotransmission, and signaling pathways implicated in Huntington's disease. J Pharmacol Exp Ther. 2011;336:64-76.

12. Rising AC, Xu J, Carlson A, Napoli VV, Denovan-Wright EM, Mandel RJ. Longitudinal behavioral, cross-sectional transcriptional and histopathological characterization of a knock-in mouse model of Huntington's disease with 140 CAG repeats. Exp Neurol. 2011;228:173-182.

13. Grauer SM, Pulito VL, Navarra RL, et al. Phosphodiesterase 10A inhibitor activity in preclinical models of the positive, cognitive, and negative symptoms of schizophrenia. J Pharmacol Exp Ther. 2009;331:574-590.

14. Strick CA, James LC, Fox CB, Seeger TF, Menniti FS, Schmidt CJ. Alterations in gene regulation following inhibition of the striatum-enriched phosphodiesterase, PDE10A. Neuropharmacology. 2010;58:444-451.

15. Rutten K, Van Donkelaar EL, Ferrington L, et al. Phosphodiesterase inhibitors enhance object memory independent of cerebral blood flow and glucose utilization in rats. Neuropsychopharmacology. 2009;34:1914-1925.

16. Piccart E, Gantois I, Laeremans A, et al. Impaired appetitively as well as aversively motivated behaviors and learning in PDE10A-deficient mice suggest a role for striatal signaling in evaluative salience attribution. Neurobiol Learn Mem. 2011;95:260-269.

17. Bahn A, Hagos Y, Reuter S, et al. Identification of a new urate and high affinity nicotinate transporter, hOAT10 (SLC22A13). J Biol Chem. 2008;283:16332-16341. 
18. Threlfell S, Sammut S, Menniti FS, Schmidt CJ, West AR. Inhibition of phosphodiesterase $10 \mathrm{~A}$ increases the responsiveness of striatal projection neurons to cortical stimulation. J Pharmacol Exp Ther. 2009;328:785-795.

19. Plisson C, Salinas C, Weinzimmer D, et al. Radiosynthesis and in vivo evaluation of $\left[{ }^{11} \mathrm{C}\right] \mathrm{MP}-10$ as a positron emission tomography radioligand for phosphodiesterase 10A. Nucl Med Biol. 2011;38:875-884.

20. Van Laere K, Ahmad RU, Hudyana H, et al. Human biodistribution and dosimetry of ${ }^{18} \mathrm{~F}-J N J 42259152$, a radioligand for phosphodiesterase 10A imaging. Eur J Nucl Med Mol Imaging. 2013;40:254-261.

21. Hu E, Ma J, Biorn C, et al. Rapid identification of a novel small molecule phosphodiesterase 10A (PDE10A) tracer. J Med Chem. 2012;55:4776-4787.

22. Tu Z, Xu J, Jones LA, Li S, Mach RH. Carbon-11 labeled papaverine as a PET tracer for imaging PDE10A: radiosynthesis, in vitro and in vivo evaluation. $\mathrm{Nucl}$ Med Biol. 2010;37:509-516.

23. Celen S, Koole M, De Angelis $M$, et al. Preclinical evaluation of ${ }^{18} \mathrm{~F}-$ JNJ41510417 as a radioligand for PET imaging of phosphodiesterase-10A in the brain. J Nucl Med. 2010;51:1584-1591.

24. Tu Z, Fan J, Li S, et al. Radiosynthesis and in vivo evaluation of $\left[{ }^{11} \mathrm{C}\right] \mathrm{MP}-10$ as a PET probe for imaging PDE10A in rodent and non-human primate brain. Bioorg Med Chem. 2011;19:1666-1673.

25. Van Laere K, Ahmad RU, Hudyana H, et al. Quantification of ${ }^{18}$ F-JNJ-42259152, a novel phosphodiesterase 10A PET tracer: kinetic modeling and test-retest study in human brain. J Nucl Med. 2013;54:1285-1293.

26. Barret $\mathrm{O}$, Thomae D, Alagille D, et al. First in vivo assessment of two PDE10 tracers $\left[{ }^{18} \mathrm{~F}\right] \mathrm{MNI}-654$ and $\left[{ }^{18} \mathrm{~F}\right] \mathrm{MNI}-659$ [abstract]. $\mathrm{J}$ Nucl Med. 2012;53(suppl 1):110P.

27. Slifstein M, Laruelle M. Models and methods for derivation of in vivo neuroreceptor parameters with PET and SPECT reversible radiotracers. Nucl Med Biol. 2001;28:595-608.

28. Logan J. A review of graphical methods for tracer studies and strategies to reduce bias. Nucl Med Biol. 2003;30:833-844.

29. Innis RB, Cunningham VJ, Delforge J, et al. Consensus nomenclature for in vivo imaging of reversibly binding radioligands. J Cereb Blood Flow Metab. 2007; 27:1533-1539.
30. Lammertsma AA, Hume SP. Simplified reference tissue model for PET receptor studies. Neuroimage. 1996;4:153-158.

31. Akaike H. A new look at the statistical model identification. IEEE Trans Automat Contr. 1974;19:716-723.

32. Fujita M, Imaizumi M, Zoghbi SS, et al. Kinetic analysis in healthy humans of a novel positron emission tomography radioligand to image the peripheral benzodiazepine receptor, a potential biomarker for inflammation. Neuroimage. 2008;40: 43-52.

33. Carson RE. Parameter estimation in positron emission tomography. In: Phelps ME, Mazziotta JC, Schelbert HR, eds. Positron Emission Tomography and Autoradiography: Principles and Applications for the Brain and Heart. New York, NY: Raven Press; 1986:347-390.

34. International Commission on Radiological Protection (ICRP). 1990 recommendations of the International Commission on Radiological Protection. ICRP publication 60. Annals of the ICRP. 1991;21.

35. International Commission on Radiological Protection (ICRP). Limits for intakes of radionuclides by workers. ICRP publication 30 (Part 1). Annals of the ICRP. 1979;2.

36. Cunningham VJ, Jones T. Spectral analysis of dynamic PET studies. J Cereb Blood Flow Metab. 1993;13:15-23.

37. Asselin MC, Montgomery AJ, Grasby PM, Hume SP. Quantification of PET studies with the very high-affinity dopamine D2/D3 receptor ligand $\left[{ }^{11} \mathrm{C}\right] \mathrm{FLB}$ 457: re-evaluation of the validity of using a cerebellar reference region. J Cereb Blood Flow Metab. 2007;27:378-392.

38. Gunn RN, Murthy V, Catafau AM, et al. Translational characterization of $\left[{ }^{11} \mathrm{C}\right]$ GSK931145, a PET ligand for the glycine transporter type 1. Synapse. 2011;65:1319-1332.

39. Turkheimer FE, Selvaraj S, Hinz R, et al. Quantification of ligand PET studies using a reference region with a displaceable fraction: application to occupancy studies with [ $\left.{ }^{11} \mathrm{C}\right]$-DASB as an example. J Cereb Blood Flow Metab. 2012;32:70-80.

40. Wu Y, Carson RE. Noise reduction in the simplified reference tissue model for neuroreceptor functional imaging. J Cereb Blood Flow Metab. 2002;22: 1440-1452. 